\title{
Erratum to: L-N-Iminoethyl-lysine after experimental brain trauma attenuates cellular proliferation and astrocyte differentiation
}

\author{
Fabian Arnberg ${ }^{1}$. Caroline Gahm ${ }^{1,2} \cdot$ Tiit Mathiesen $^{1}$
}

Published online: 19 April 2015

(C) Springer-Verlag Wien 2015

Erratum to: Acta Neurochir (2012) 154:681-687

DOI 10.1007/s00701-012-1282-8

The original version of this article unfortunately contained mistakes. The names of all authors are inadvertently inverted and are now corrected in the authorgroup of this article.

The online version of the original article can be found at http://dx.doi.org/ 10.1007/s00701-012-1282-8.

\footnotetext{
Fabian Arnberg

fabian.arnberg@ki.se
}

1 Department of Clinical Neuroscience, Section of Clinical CNS Research, Karolinska Institutet, 17176 Stockholm, Sweden

2 Department of Clinical Neuroscience, Section of Oto-RhinoLaryngology, Karolinska University Hospital, Huddinge, Stockholm, Sweden 